\title{
ОСОБЕННОСТИ КОМПЛЕКСА МАРКЕТИНГА НА МЕЖДУНАРОДНОМ РЫНКЕ ПАССАЖИРСКИХ АВИАПЕРЕВОЗОК
}

\author{
О. Н. Беленов, Ю. В. Шурчкова
}

Воронежский государственный университет

Поступила в редакцию 5 ноября 2019 г.

\begin{abstract}
Аннотация: проводится анализ характерных изменений, происходящих в традиционном комплексе маркетинга, под влиянием отраслевой специфики рынка пассажсрских авиаперевозок. Рассматривается данный процесс трансформации комплекса маркетинга как на внутреннем, так и на международном рынках.
\end{abstract}

Ключевые слова: комплекс маркетинга, международный рынок, пассажирские авиаперевозки.

Annotation: the article is devoted the characteristic changes occurring in the traditional marketing complex, under the influence of industry specifics of the passenger air transportation market. This process of transformation of a complex of marketing both in domestic, and in the international markets is considered.

Key words: marketing complex, international market, passenger air transportation.

Одной из основных тенденций современной экономики в последние десятилетия стал активный рост сферы услуг. В европейских странах, Америке и Японии количество работников, вовлеченных в сектор услуг, превышает число людей, работающих во всех других секторах экономики. Сфера услуг в этих странах приносит до 60-70 \% национального дохода. В международной торговле услуги составляют 20 \% всего мирового экспорта. Данные изменения привели к возрастанию интереса к особым проблемам маркетинга услуг.

Рынок услуг различается огромным многообразием и в то же время распадается на более узкие сегменты: технологий, туризма, транспортных, информационных и других услуг. Одной из отличительных черт рынка услуг является его диверсификация [1].

Международный маркетинг в сфере услуг следует рассматривать как составляющую системы знаний в отрасли маркетинга. Его базой являются факторы пространственно-географического порядка, которые связаны с деятельностью предприятий на рынках других стран, в том числе если он дополняет внутренний маркетинг на национальном уровне. Международный маркетинг услуг предполагает систематическую, плановую и активную обработку международных рынков на различных стадиях продвижения к покупателю и выражает масштабность зарубежной деятельно-

(С Беленов О. Н., Шурчкова Ю. В., 2020 сти фирмы. Это может быть двусторонний процесс, когда предприятие, освоившее рынок своей страны, выходит на рынок другого государства. Однако часто используются многосторонние системные действия, характеризующиеся тем, что компания присутствует на многих рынках. Более того, для каждого зарубежного рынка должна быть тщательно спланирована маркетинговая программа. Как правило, на рынке услуг используются два вида маркетинговых комплексов. Стандартизованный маркетинговый комплекс - стратегия использования одной и той же продукции, рекламы, каналов сбыта и других элементов маркетингового комплекса на всех международных рынках компании. Стратегии стандартизации услуги позволяют создать международный имидж продукта, сократить расходы на разработку и производство рекламы, ускорить синхронный выход на рынки разных стран.

Адаптированный маркетинговый комплекс в сфере услуг предопределяется, по мнению исследователей, следующими факторами: наличие однородных потребностей и предпочтений, мобильность потребителей, достижение эффект масштаба/опыта, снижение затрат, технологические возможности.

Однако есть целый ряд примеров того, как одна и та услуга модифицируются в зависимости от требований местных рынков. Основные стратегии адаптации услуги и ее продвижения на зарубежном рынке приведены в табл. 1. 
Стратегии адаптаџии услуги на зарубежном рынке

\begin{tabular}{|l|l|}
\hline \multicolumn{1}{|c|}{ Стратегия } & \multicolumn{1}{|c|}{ Описание } \\
\hline Прямое распределение & Предложение внешнему рынку услуги без изменений \\
\hline $\begin{array}{l}\text { Частичная адаптация комплекса } \\
\text { маркетинга }\end{array}$ & $\begin{array}{l}\text { Адаптация некоторых элементов комплекса маркетинга, как правило, эле- } \\
\text { ментов продвижения }\end{array}$ \\
\hline $\begin{array}{l}\text { Полная адаптация комплекса мар- } \\
\text { кетинга }\end{array}$ & $\begin{array}{l}\text { Адаптация всех элементов комплекса маркетинга в соответствии с услови- } \\
\text { ями конкретной страны и предпочтениями внешних потребителей }\end{array}$ \\
\hline $\begin{array}{l}\text { «Обратное» изобретение или но- } \\
\text { вое изобретение }\end{array}$ & $\begin{array}{l}\text { Предложение устаревшей услуги в развивающихя странах или разработ- } \\
\text { ка и предложение на внешнем рынке новой услуги }\end{array}$ \\
\hline
\end{tabular}

В процессе деятельности на международном рынке фирма стремится к достижению поставленных целей, реализуя следующие типы стратегий:

1) атакующая стратегия - когда действия компании направлены на завоевание и расширение рыночной доли. По данным маркетинговых исследований, увеличение рыночной доли на $10 \%$ сопровождается ростом нормы ее прибыли в среднем на $5 \%$;

Компания может выбрать атакующую стратегию на международном рынке:

- если ее доля на рынке ниже необходимого минимума или резко сократилась в результате действий конкурентов и не обеспечивает достаточного уровня прибыли;

- конкуренты теряют свои позиции и создается возможность расширить рыночную долю за счет небольших затрат;

2) оборонительная стратегия - предполагает сохранение компанией имеющейся рыночной доли и удержание своих позиций на международном рынке; компании выбирают ее:

- если рыночная позиция компании удовлетворительна или для проведения атакующей агрессивной политики нет средств;

- предвидятся ответные меры конкурентов или государства и компания к ним готовится;

3) стратегия отступления как вынужденная мера. Эта стратегия предполагает два варианта действий: постепенное свертывание операций или ликвидация бизнеса на международном рынке [2].

Также необходимо отметить, что традиционный комплекс маркетинга в условиях оказания услуг расширяется с учетом трех дополнительных элементов, которые включают:

- персонал (имеющий отношение к процессу купли-продажи);

- процесс оказания услуги (действия, связанные с деятельностью покупателя по осуществлению выбора услуги);

- физическое доказательство факта оказания услуги (материальный предмет, который может служить для клиента подтверждением факта оказания услуги) [3, с. 278-280].

Авиакомпании перешли к концепции управления на основе принципов маркетинга сравнительно недавно - в конце 1960-х гг. В послевоенные годы развитие гражданской авиации осуществлялось в основном по пути экстенсификации, в направлении стремительного наращивания производственно-технического потенциала воздушного транспорта. В условиях повышенного спроса на авиаперевозки и жесткого регулирования авиакомпании осуществляли свою деятельность, не задумываясь о привлечении клиентов.

Возможности гражданской авиации существенно расширились в конце 1960-х - начале 1970-х гг. с появлением широкофюзеляжных самолетов большой вместимости. В этих условиях проблема технического развития воздушного транспорта отошла на второй план, уступив место проблеме повышения экономической эффективности эксплуатации авиалиний, стимулированию спроса на услуги авиакомпаний. Крупнейшие авиакомпании перешли к маркетинговой концепция управления, предполагающей ориентацию деятельности на конъюнктуру рынка и динамику спроса, приспособление производства и финансирования к потребностям рынка, создание условий, стимулирующих спрос, разработку способов воздействия на потенциальных клиентов [4].

Рынок пассажирских авиаперевозок цикличен, поскольку объем спроса на авиаперелеты крайне чутко реагирует на функционирование экономики. Особенности авиатранспортного маркетинга в значительной степени обусловлены спецификой отрасли, которая имеет сложную структуру, где переплетаются разнообразные внутренние и внешние связи.

Рынок авиаперевозок достаточно специфичен с точки зрения трансформации элементов комплекса маркетинга. Современные авиакомпании реализуют различные бизнес-модели. Как отмечает 
А. В. Андреев, в зависимости от ширины маршрутной сети (количества направлений, по которым выполняются перевозки) и глубины маршрутной сети (частоты выполнения рейсов в рамках действующего расписания) это могут быть чартерные авиакомпании, бизнес-авиакомпании, сетевые, региональные, авиакомпании географической (брендовой) ниши, грузовые, низкозатратные [5, c. 200]. Очевидно, для каждой из реализуемых бизнес-моделей будет характерна своя стратегия в области комплекса маркетинга. Остановимся подробно на основных элементах комплекса маркетинга, имеющих специфику как для рынка авиаперевозок, так и для конкретной бизнес-модели.

Ценообразование. Одним из главных условий рациональной организации деятельности транспорта и его прибыльности является грамотное, качественное и планомерное формирование цен на транспортные услуги. Кроме того, там, где невозможно создать конкурентную среду, проводят сбалансированную тарифную политику государства. Роль транспортного тарифа-платы за услуги по переезду в деятельности того или иного вида транспортной компании трудно переоценить, поскольку от уровня тарифов зависит прибыльность, а следовательно, и финансовая устойчивость конкурентоспособности.

Спрос и, как следствие, тариф перевозчика зависят от целого ряда факторов, среди которых необходимо выделить следующие [6].

1. Наличие сезонности. На рынке пассажирских авиаперевозок имеет место «высокий» сезон, когда повышается мобильность и множество людей совершают перелеты: Новый год, майские праздники (в РФ и некоторых странах СНГ), летние каникулы. Однако существует и «низкий» сезон, когда люди летают меньше (зимой). Высокая сезонность снижает доходность авиаперевозок, приводя к избытку провозных мощностей и низким ценам на авиабилеты. Поэтому в «низкий» сезон авиакомпании генерируют убытки, покрывая его за счет высокого спроса и значительного увеличения цены на билеты в «высокий» сезон. В среднем рост цен на авиабилеты в период с начала мая до середины июня и со второй половины сентября по середину октября составляет около $30 \%$; со второй половины июня до середины сентября рост цен может доходить до $95 \%$. Сезонность заставляет авиакомпании делать стратегический выбор: в первом случае - расширить долю рынка в «высокий» сезон и получить низкую загрузку и убытки в «низкий» сезон; во втором случае - потерять долю рынка в «высокий» сезон, но сохранить определенный уровень рентабельности в «низкий» сезон за счет баланса провозных мощностей.

2. Дни недели: обычно в будние дни спрос ниже, чем в выходной день, и цена билета может быть ниже.

3. Время суток: есть более и менее популярные рейсы в зависимости от времени вылета воздушного судна.

4. Даты бронирования: авиакомпании стремятся продать билеты на рейс как можно раньше, поэтому они поощряют пассажиров покупать их заранее. Авиакомпании планируют, сколько мест и по какой цене продавать. Например, для продажи по минимальной стоимости выделяется 20 посадочных мест. Как только они будут забронированы, цена начинает увеличиваться.

5. Количество и качество конкурентных предложений от авиакомпаний по конкретному направлению: чем больше перевозчиков работают на определенном маршруте, тем выше конкуренция и больше предложений дешевых авиабилетов, специальных тарифов, распродаж, акций.

6. Наличие или отсутствие связи с альтернативными видами транспорта, например железнодорожным.

7. Курс рубля относительно доллара и евро оказывает прямое влияние на цену билета, так как все расчеты авиакомпаний осуществляются в валюте по внутреннему курс Международной ассоциации воздушного транспорта (IATA). Это в первую очередь затрагивает цены перелета на международных рейсах, а также перелетов на рейсах иностранных компаний. Авиакомпании чувствительны к колебаниям валютного курса, поскольку около половины затрат, в том числе на лизинг, топливо и запчасти, напрямую связаны с курсом рубля.

Авиакомпании, по сути, - производители сложных и комплексных услуг, и в этом случае «издержки производства» могут включать тип самолета, количество мест, прогноз загрузки пассажиров; стоимость аэронавигационного обслуживания; стоимость аэропортовых услуг; дальность полета, расход топлива на километр; расходы, связанные с персоналом, обучением экипажа, размещением персонала в принимающей стране; прочие расходы. Кроме того, на цену билета может повлиять реализуемая маркетинговая стратегия компании.

Существует несколько классификаций тарифов пассажирских авиаперевозок. Различают тарифы опубликованные и конфиденциальные. 
Опубликованные тарифы авиакомпаний контролируются Международной ассоциацией воздушного транспорта и используются в основном для расчета сложных маршрутов с участием нескольких перевозчиков. Билеты по опубликованным тарифам на самолет можно приобрести в любой точке мира, однако их цена, как правило, достаточно высока [7]. Конфиденциальные тарифы формируются авиакомпаниями самостоятельно, с учетом спроса, конкуренции и стратегии компании в отдельное направление. Такие тарифы являются коммерческой тайной для конкурентов. Они эксплуатируются самой авиакомпанией и ее агентами. Такие тарифы являются коммерческой тайной для конкурентов, они действуют на саму авиакомпанию и ее агентов. Конфиденциальные тарифы действуют, например, когда потребитель приобретает билет в оба конца у одной авиакомпании.

Отдельно стоит рассматривать такой тип авиаперевозчиков, как лоукостеры (низкозатратные авиакомпании). Лоукостеры - это авиакомпании, предоставляющие услуги авиаперевозок для пассажиров по ценам ниже традиционных авиакомпаний. Концепция лоукост зародилась в США, а именно в компании Southwest Airlines, из которой она распространилась в Европу в начале 1990-х гг. и далее во многие страны мира. В РФ в настоящее время лоукостером является компания «Победа».

На ценообразование в бюджетных авиалиниях влияют многие факторы [8]. Первый фактор - это высокая загрузка самолетов. Один самолет в лоукостере выполняет множество рейсов в день, и компания иногда готова продать билет по минимальной цене. Второй фактор - билет на самолет не включает дополнительных услуг, а перевозка багажа, еда, напитки и прочие услуги предлагаются за дополнительную плату. Третий фактор использование аэропортов. Дешевые авиалинии часто базируются в небольших аэропортах, а основные транспортные узлы либо обходят стороной, либо арендуют на полчаса. Небольшие аэропорты в небольших городах стоят намного дешевле, а некоторые даже готовы доплачивать перевоз- чику, надеясь, что таким образом увеличится туристический поток в конкретном городе.

Низкозатратные авиакомпании ведут бизнес более эффективно, чем традиционные, получая больший налет на единицу парка воздушных средств, больше доходов на одного работника и меньше расходов на каждое пассажироместо. Это достигается за счет использования современного авиапарка с меньшим потреблением топлива, исключения расходов на необязательные элементы сервиса (использование бизнес-залов в аэропортах, начисление миль за частые полеты и т. п.), использования меньшего количества персонала, продаж авиабилетов через интернет (расходы традиционной авиакомпании на комиссионное вознаграждение или содержание городских авиакасс составляют около $10 \%$ стоимости билета), взимания платы за регистрацию в аэропорту, а не через интернет и т. д. [5].

Лоукостеры не летают по сложным маршрутам, не обеспечивают стыковок с сетевыми авиакомпаниями со сквозной регистрацией и обработкой багажа. Однако, как показывает мировая практика, это одна из наиболее эффективных в сегодняшних условиях моделей авиабизнеса, имеющая высокий потенциал дальнейшего развития, в том числе в России.

В последние годы в процессе ценообразования также наметилась тенденция ориентации тарифов на платные пакетные услуги. В ближайшие годы прогнозируется снижение удельного расхода топлива в расчете на одного пассажира.

При расчетах тарифов на пассажирские авиаперевозки за основу принимается показатель доходной ставки на 1 пассажирокилометр, а также рассматривается стоимость 1 тонны авиационного керосина [4]. В табл. 2 представлена средняя стоимость перевозки авиакомпаниями РФ в период с 2013 по 2016 г.

Необходимо отметить, что процент загрузки для обеспечения безубыточности перевозки (показатель BLF), также являющийся фактором ценообразования на услуги авиаперевозчиков, в России и Европе составляет 63 \%, в Северной Америке -

Т а б ли ц а 2

Средняя стоимость перевозки авиакомпаниями РФ, 2013-2016 г2., руб.

\begin{tabular}{|c|c|c|c|c|}
\hline \multirow{2}{*}{ Показатель } & \multicolumn{4}{|c|}{ Год } \\
\cline { 2 - 5 } & 2013 & 2014 & 2015 & 2016 \\
\hline Внутренние перевозки & 6698 & 6297 & 6517 & 5712 \\
\hline Международные перевозки & 7145 & 7372 & 8618 & 8299 \\
\hline Средневзвешенная цена & 6773 & 6428 & 6714 & 5892 \\
\hline
\end{tabular}


$55,5 \%$, на Ближнем Востоке - 57,8 \%, в Африке и Азиатско-Тихоокеанском регионе $-61,7 \%$.

Кроме ценообразования и системы комиссионных и бонусных вознаграждений, которая представляет собой базовую составляющую коммерческой политики авиакомпаний, необходимо принимать во внимание и другие направления данной политики, в частности, политику по реализации коммерческих прав пятой «свободы воздуха», политику по использованию права свободной продажи, прорейтовую политику, политику по работе с агентами, по коммерческому сотрудничеству с авиакомпаниями, работу в области планирования перевозок и соотношения регулярных и чартерных рейсов $[9$, с. 54].

Одним из методов повышения рентабельности и эффективности ценовой политики авиакомпания является динамическое ценообразование, применяемое в последнее время также при осуществлении железнодорожных перевозок. При динамическом ценообразовании стоимость билета оперативно изменяется в зависимости от даты вылета и загрузки провозной емкости воздушного судна. Самый существенный рост прослеживается в последние 3-4 дня перед вылетом. Среднее значение роста цен на билеты составляет: $12 \%$ - за 7-14 дней до вылета; 21,2 \% - за 4-6 дней до вылета; $110 \%$ - за 1-3 дня до вылета. В среднем годовой уровень цен на билеты увеличивается при применении динамического ценообразования более чем на $12 \%$ [10].

Товарная политика. Первичный продукт авиакомпаний - это услуга по перевозке пассажира до пункта назначения. Второстепенными услугами являются бронирование, перевозка багажа, предоставление наземного сервиса и на борту самолета.

Услуги авиаперевозчиков специфичны не только в силу тех особенностей, которые присущи всем услугам в целом (неосязаемость, несохраняемость, сложность сравнения, неотделимость от источника услуги и пр.). К основным параметрам услуг авиакомпаний, влияющих на уровень их конкурентоспособности, необходимо также отнести степень комфортабельности салонов воздушного судна, возможность беспосадочного перелета в пункт назначения, внимательность бортпроводников, удобство расписания, наличие и особенности питания во время полета, тип воздушного судна, имидж авиакомпании, наземное обслуживание в аэропорту [5]. Как показывают маркетинговые исследования, проводимые в области международных авиаперевозок, к наиболее значимым параметрам продукции в данном случае респонденты относят безопасность (10,5 \% опрошенных), пунктуальность авиакомпании (10,3\% опрошенных) и цену билета (10,2\% опрошенных). В табл. 3 представлены лидеры по безопасности перелетов в 2018 г. по версии немецкой компании JACDEC.

Наименее значимые параметры при оценке качества услуг авиаперевозчиков - это имидж (7,2 \% опрошенных) и наземное обслуживание (6,1\% опрошенных).

Большинство авиакомпаний имеют «полноценную» продукцию, включающую пассажирские и грузовые перевозки, выполняемые по расписанию и на регулярной основе. Также предусмотрены стандарты предоставления качественных характеристик продукции на целевых рынках и высокий уровень сервиса и комфорта как при наземном обслуживании, так и в полете. Как правило, крупные компании разрабатывают и поддерживают собственную модель взаимодействия с потребителями (программы для часто летающих пассажиров и т. д.).

Авиакомпании, ведущие свой бизнес согласно модели географической (брендовой) ниши, исполь-

Т а бли ц а 3

Авиакомпании - лидеры по безопасности перелетов в 2018 г.

\begin{tabular}{|c|l|l|c|}
\hline № & \multicolumn{1}{|c|}{ Авиакомпания } & \multicolumn{1}{c|}{ Страна } & Индекс безопасности \\
\hline 1 & Cathay Pacific Airway & Китай, Гонконг & 0,006 \\
\hline 2 & Emirates & ОАЭ & 0,007 \\
\hline 3 & Eva Air & Тайвань & 0,008 \\
\hline 4 & Qatar Airways & Катар & 0,009 \\
\hline 5 & Hainan Airlines & Китай & 0,01 \\
\hline 6 & KLM & Нидерланды & 0,01 \\
\hline 7 & Air New Zeland & Новая Зеландия & 0,011 \\
\hline 8 & Etihad Airways & ОАЭ & 0,013 \\
\hline 9 & Japan Airlines & Япония & 0,015 \\
\hline 10 & TAP Portugal & Португалия & 0,016 \\
\hline
\end{tabular}


зуют четко выраженные характерные особенности своей торговой марки и применяют различные инновации, повышающие качество обслуживание и конкурентоспособность своих услуг. Они имеют четкие географические (продуктовые) границы и концентрируются на специфических магистральных авиаперевозках и специфическом обслуживании.

Чартерные авиакомпании концентрируются на низких издержках производства и максимизации прибыли от выполненного рейса, что достигается использованием наиболее вместительных вариантов компоновки воздушного средства максимально высоким коэффициентом коммерческой загрузки. Качество перевозки на таких воздушных судах является второстепенным фактором, а класс компоновки салонов ограничивается категорией «эконом» с минимальным шагом кресел в салонах.

Бизнес-авиакомпании (VIP) ориентированы на использование специально оборудованных комфортабельных воздушных судов. В стандарты VIP-обслуживания входят отдельное оформление документов без очередей, возможность связаться с партнерами с борта самолета, особое питание и др.

В последние несколько лет основными направлениями развития услуг авиаперевозчиков можно считать сокращение уровня бесплатного питания на борту судна, снижение времени оборота судна на земле до менее 45 минут, использование политики агрессивного маркетинга, повышение всех видов производительности, дифференциация услуг за дополнительную плату, кооперирование с туроператорами, предоставление аудио и видео на борту. Необходимо отметить, что модели авиакомпаний действуют на разных типах конкурентных рынков и имеют различия в конкурентных преимуществах в связи с различиями в требованиях целевых аудиторий к цене и качеству услуг.

Место. В данном случае речь идет о расположении аэропорта, офисов продаж авиакомпании и ее агентов по продаже авиабилетов. Также авиакомпания должна выбрать каналы реализации авиабилетов и распределить ресурс мест между агентами и собственной продажей и рассмотреть возможность прямой продажи. Одним из направлений повышения удовлетворенности клиента местом оказания услуг авиакомпаний является внедрение различного рода мобильных приложений в деятельность аэропортов и авиакомпаний.

Продвижение. Для привлечения клиентов авиаперевозчики используют различные виды рекламы, которая является одной из самых важных инструментов продвижения на рынке авиационных перевозок. Авиакомпании по всему миру затрачивают огромные средства на печатную рекламу, радио-, теле- и интернет-рекламу. Например, затраты авиакомпаний на продвижение составляют до 14 \% от всех эксплуатационных расходов, а годовой бюджет американских авиакомпаний на рекламу составляет свыше 10 млн долл. [11, с. 12-13].

Большое внимание уделяется имиджу и узнаваемости компании. Целевые аудитории определяют средства маркетинговых коммуникаций. Для привлечения внимания деловых авиапассажиров используются бизнес-ориентированные издания, для авиапассажиров-туристов более значимы специализированные журналы. Интернет представляет собой еще один эффективный рекламный канал: сообщения доносят информацию о наилучших маршрутах. Если авиакомпания ставит перед собой долгосрочную цель по построению узнаваемого бренда, телевизионная реклама также оправдает вложения.

Один из лидеров российского рынка гражданской авиации авиакомпания S7 Airlines, проводя рекламную кампанию «Свобода выбирать», успешно использовала как телерекламу, так и печатные СМИ. Также маркетинговые коммуникации осуществлялись посредством радио для розыгрыша годового билета на авиаперелеты S7 Airlines. Компания «Аэрофлот - российские авиалинии», проводя свою рекламную кампанию То Asia from Moscow, для размещения информации использовала такси в Лондоне. Была задействована и наружная реклама, реклама на печатных материалах и в бортовых журналах авиакомпании. Рекламная информация размещалась на авиабилетах и спинках кресел в самолетах. Кампания также преследовала цель развития аэропортов Москвы как международных узлов для поощрения транзита между Европой и Азией. Общий бюджет кампании составил 15 млн долл.

Также эффективным приемом продвижения авиакомпаний является их участие в специализированных выставках, конкурсах, рейтингах. Одна из таких выставок - Национальная выставка инфраструктуры гражданской авиации NAIS-2017 ежегодно подводит итоги конкурса на лучшую авиакомпанию Skyway Service Award, которую выбирают пассажиры с учетом качества обслуживания, безопасности, работы терминалов и пр. Среди выставочных событий наибольший интерес представляют следующие выставки авиации: HELI-EXPO - ежегодная конференция и специализированная выставка Международной вертолет- 
ной ассоциации, АВАСЕ - Азиатская выставка и конференция бизнес-авиации, AERO - ведущая европейская торговая выставка общей авиации, ILA Berlin Air Show - Международная берлинская аэрокосмическая выставка и конференции, JET ЕХРО - Международная выставка деловой авиации, МАКС - Международный авиационно-космический салон (Авиасалон MAKC), INTER AIRPORT CHINA - Международная выставка оборудования для аэропортов, технологий и услуг, FARNBOROUGH AIRSHOW - Международный авиационно-космический салон в Фарнборо и др.

Социальные сети также все чаще становятся важным средством коммуникации для индустрии авиаперевозок. Первоначально использовались такие сайты, как Facebook, Twitter и Myspace. Как показывают исследования, обмен и сбор эксклюзивной информации через социальные сети помогает уменьшить рекламные бюджеты и, в свою очередь, увеличить доход и повысить лояльность к бренду. Крупные авиакомпании, такие как JetBlue, Virgin America и British Airways, начали использование социальных сетей, и в короткие сроки добились повышения удовлетворенности клиентов, снижения затрат и повышения лояльности к бренду. По данным глобального онлайн-исследования Nielsen, около 70 \% населения мира посещают сайты социальных сетей, напримep Facebook и MySpace, или сайты блогов [12].

В авиационной отрасли сайты социальных сетей используются для упрощения контактов с клиентами и реагирования на их запросы путем упреждающего мониторинга и ответов в онлайн-чате. Сайты социальных сетей имеют возможность привлечь внимание потребителей при помощи показа баннеров, информации и т. д. Социальные сети могут быть

\section{ЛИТЕРАТУРА}

1. Нагапетьяни Н. А. Международный маркетинг : учеб. пособие / Н. А. Нагапетьянц, О. Н. Романенкова, Н. Г. Каменева, С. В. Земляк. - М. : Вузовский учебник, НИЦ ИНФРА-М, 2013. - 292 с.

2. Диденко Н. И. Международный маркетинг : учебник для бакалавров / Н. И. Диденко, Д. Ф. Скрипнюк ; отв. ред. Н. И. Диденко. - М. : Юрайт, 2012. - 556 с.

3. Котлер Ф. Маркетинг менеджмент. Экспресскурс / Ф. Котлер, К. Л. Келлер. - 3-е издание. - СПб. : Питер, 2012. - 810 с.

4. Костромина Е. В. Авиатранспортный маркетинг / Е. В. Костромина. - М. : ИНФРА-М, 2018. - 360 с.

5. Андреев А. В. Бизнес-модель авиакомпании как инструмент реализации ее конкурентной стратегии в использованы, чтобы получить первоначальное внимание к компании, публикуя фотографии, видео, рекламу, текущие новости компании; могут способствовать росту продаж, направляя потребителей на сайты поиска электронных билетов или турагентств.

Немедленная обратная связь на основе социальных сетей повышает скорость реагирования на запросы пассажиров, которые потеряли свой багаж или пропустили рейс. Британские бюджетные перевозчики, такие как easyJet, имеют более 70 тыс. подписчиков в Twitter, Virgin Atlantic и airBaltic более 20 тыс. Facebook чаще используется в качестве платформы для продвижения американскими авиакомпаниями, которые совместными усилиями запустили приложение Travelbag, где пользователи могут поделиться своим опытом путешествия, а также запланировать предстоящие события или поездки. По данным авиакомпании, они пытаются дифференцировать и сегментировать своих пассажиров вместе с выявлением их покупательских предпочтений.

Бронирование билетов через интернет также может быть ускорено социальными сетями, так как большинство авиакомпаний продают и продвигают свои билеты с помощью социальных сетей. Например, с помощью JetBlueCheeps - потока Twitter, посвященного продажам билетов за несколько часов до вылета.

В целом трансформация элементов комплекса маркетинга в сфере авиаперевозок по каждому из элементов достаточно существенна по сравнению с прочими видами услуг. Особенно серьезно она затрагивает ценообразование и товарную политику, каналы распределения также приобретают специфический вид и содержание. Продвижение же авиакомпаний в основном соответствует тенденциям в других сферах, связанных с оказанием услуг.

условиях современного авиатранспортного рынка / A. В. Андреев // TRANSPORT BUSINESS IN RUSSIA. 2011. - № 9. - C. 199-203.

6. Серемина Р. Н. Особенности формирования российского рынка авиаперевозок / Р. Н. Серемина // Инновационная экономика : материалы Междунар. науч. конф. (г. Казань, октябрь 2014 г.). - Казань : Бук, 2014. C. 219-221.

7. Тультаев T. А. Влияние маркетинговой деятельности на развитие транспортных услуг в России / Т. А. Тультаев, С. И. Зубин // Науковедение. - 2013. № 6 (19). - С. 104.

8. Брусиловский Е. В. Авиационный бизнес и воздушные суда / Е. В. Брусиловский. - М. : Контент-пресс, 2012. -496 c. 
9. Коммерческая деятельность на воздушном транспорте : учеб. пособие / сост. Л. Б. Бажов. - Ульяновск : УВАУ ГА, 2006. - 119 с.

10. Фридлянд A. А. Текущая ситуация и тенденции на российском авиатранспортном рынке / А. А. Фридлянд, А. В. Андреев, А. В. Кузьмин // Aviation Explorer от 9 октября 2017 г.

11. Афанасьев В. Г. Некоторые маркетинговые методы управления конкурентоспособностью авиакомпа-

Воронежский государственный университет

Беленов О. Н., доктор экономических наук, профессор, начальник управления по международному сотрудничеству, декан факультета международньх отношений

E-mail: belenov@vsu.ru

Тел.: +7 (473) 220-88-69

Шурчкова Ю. В., кандидат экономических наук, доиент кафедры международной экономики и внешнеэкономической деятельности факультета международных отношений

E-mail: jshurchkova@mail.ru нии на внешних рынках / В. Г. Афанасьев // Научный вестник Московского государственного технического университета гражданской авиации. - 2009. - № 146. C. 11-16.

12. Костин $A$. $A$. Специфика рекламной кампании российских авиаперевозчиков / А. А. Костин // Актуальные проблемы авиации и космонавтики. - 2017. № 13. - С. 1079-1081.

Voronezh State University

Belenov O. N., Dr. in Economics, Professor, Head of International Cooperation Department, Dean of the International Relations Faculty

E-mail:belenov@vsu.ru

Tel.: +7 (473) 220-88-69

Shurchkova U. V., PhD in Economics, Associate Professor of of the Department of International Economics and Foreign Economic Activity

E-mail:jshurchkova@mail.ru 